\title{
Strategi Bertahan Subak di Daerah Pariwisata (Kasus Subak Semujan, Kecamatan Ubud, Kabupaten Gianyar)
}

\author{
I GUSTI NGURAH BAGUS SUPARDI PUTRA, \\ I KETUT SURYA DIARTA, WAYAN SUDARTA
}

\author{
Program Studi Agribisnis, Fakultas Pertanian, Universitas Udayana \\ Jl. PB. Sudirman Denpasar 08323 \\ E-mail: supardiputra15@gmail.com \\ suryadiarta_unud@yahoo.com
}

\section{Abstract \\ The Survival Strategies of Subak in the Tourism Area (in the Case of Subak of Semujan, Subdistrict of Ubud, Regency of Gianyar)}

Subak Semujan is a subak located in Ubud tourism center, now it is threatened by tourism itself. From 2012 to 2016 Subak Semujan has undergone land conversion of 15 hectares. This decrease is due to the conversion of agricultural land into tourism facilities such as hotels, bungalows, restaurants, and villas. The purpose of this research is to design the survival strategies of Subak of Semujan in the tourism area. Result of internal factor analysis Subak Semujan: a) strength: religious ceremony, awig-awig and pararem (traditional customs and rules), b) weakness: lack of interest of the farmers' children in the agricultural field, adopting lower innovation or technology. External factors: a) opportunities: social assistance and rice production facilities, farming extension, b) threats: tourism businesses require agricultural land, tourism employment opportunities. Based on the SWOT analysis, survival strategies are: a) S-O strategy of agricultural extension activities to be able to maintain agriculture in tourism area and to promote farming activities in the form of tour packages, b) S-T strategy: to make special rules related to land conversion and irrigation channel (awig-awig), c) W-O strategy: education and training through extension in adopting new innovations, agricultural extension for the younger generation, d) W-T Strategy: giving material and non-material incentives to the members of subak.

Keywords: strategies, subak, tourism, and SWOT analysis.

\section{Pendahuluan}

\subsection{Latar Belakang}

Subak sebagai suatu sistem irigasi merupakan teknologi sepadan yang telah menyatu dengan sosio-kultural masyarakat Bali. Kesepadanan teknologi sistem subak ditujukan oleh anggota subak tersebut melalui pemahaman terhadap cara pemanfaatan air irigasi yang berlandaskan Tri Hita Karana (THK) yang menyatu dengan cara membuat bangunan dan jaringan fisik irigasi, cara mengoperasikan, koordinasi pelaksanaan operasi dan pemeliharaan yang dilakukan oleh pekaseh (ketua subak), bentuk kelembagaan, dan informasi untuk pengelolaannya (Pitana, 1993). Lebih lanjut, Windia (2016) menyatakan bahwa subak merupakan sistem budaya masyarakat yang memiliki tiga subsistem yakni subsistem budaya (termasuk pola pikir, norma, dan nilai), 
subsistem sosial (termasuk ekonomi), subsistem kebendaan (temasuk teknologi). Subak seiring berkembangnya pembangunan pada era modernisasi sekarang ini mulai mengalami ancaman alih fungsi lahan pertanian ke non pertanian. Salah satu subak di Bali yang mulai terancam adalah Subak Semujan yang terletak di pusat pariwisata Ubud tepatnya di Kecamatan Ubud, Kabupaten Gianyar yang sekarang ini terancam oleh pariwisata. Berdasarkan data yang diperoleh dari pekaseh Subak Semujan I Nyoman Sudariasta dan BPP Kecamatan Ubud dari tahun 2012 sampai dengan tahun 2016, luas garapan sawah mengalami penyusutan sebanyak lima hektar. Penurunan ini disebabkan adanya alih fungsi lahan pertanian menjadi fasilitas pariwisata seperti hotel, bungalow, restaurant, dan villa. Melihat hal tersebut, sangat penting untuk mempertahankan subak karena subak memiliki banyak fungsi baik secara internal maupun eksternal (Sudarta dan Dharma, 2013 dalam Budiastuti, 2015). Melihat kondisi dan masalah yang ada tersebut maka diperlukan strategi bertahan karena subak merupakan salah satu dari warisan budaya yang harus dijaga kelestariannya.

\subsection{Rumusan Masalah}

Berdasarkan latar belakang masalah yang sudah dijelaskan sebelumnya dapat dirumuskan masalah bagaimana strategi Subak Semujan dalam bertahan di daerah pariwisata?

\subsection{Tujuan Penelitian}

Adapun tujuan penelitian ini untuk merancang strategi Subak Semujan dalam bertahan di daerah pariwisata.

\section{Metode Penelitian}

\subsection{Lokasi dan Waktu Penelitian}

Lokasi penelitian dilaksanakan di Subak Semujan, Kecamatan Ubud, Kabupaten Gianyar dengan pertimbangan (1) merupakan salah satu subak di daerah pariwisata Ubud yang terancam oleh pariwisata seperti alih fungsi lahan, pencemaran saluran air irigasi dan berkurangnya generasi muda pertanian, (2) terjadi alih fungsi lahan pertanian seluas lima hektar terhitung dari tahun 2012 sampai dengan 2016, dan (3) belum pernah ada penelitian sejenis di Subak Semujan. Penelitian ini berlangsung dari bulan Agustus sampai dengan Desember tahun 2017, terhitung dari survei pendahuluan sampai dengan penyelesaian pengambilan data penelitian.

\subsection{Jenis dan Sumber Data}

Jenis data yang dipergunakan dalam penelitian ini meliputi data kualitatif dan kuantitatif.

1. Data kualitatif berupa narasi atau data yang tidak dapat dihitung dengan satuan hitung, seperti uraian-uraian, narasi atau keterangan (bukan angka) yang bersumber dari pekaseh, pengurus subak, dan petani sebagai anggota Subak Semujan (Sugiyono, 2012).

2. Data kuantitatif yaitu data yang berupa angka-angka dan dapat dihitung, seperti jumlah anggota Subak Semujan dan data luas Subak Semujan. Sumber data yang dipergunakan dalam penelitian ini mencakup data primer dan sekunder (Sugiyono, 2012).

Sumber data yang dipergunakan dalam penelitaian ini mencakup data primer dan sekunder sebagai berikut. 
1. Data primer adalah sumber data yang diperoleh secara langsung dari sumber aslinya (Maulidi, 2016). Data primer diperoleh dari hasil wawancara mendalam dengan informan kunci, observasi di Subak Semujan, dan wawancara menggunakan pedoman wawancara. Data sekunder merupakan data yang diperoleh dari sumber pustaka, catatan dari pustaka ilmiah, dan dokumendokumen yang berhubungan dengan penelitian yang dilakukan.

2. Data sekunder yang dikumpulkan antara lain, jumlah anggota Subak Semujan, awig-awig Subak, data luas lahan subak, dan data jumlah penduduk di Kelurahan Ubud dari Profil Kecamatan Ubud.

\subsection{Metode Pengumpulan Data}

Metode pengumpulan data yang digunakan dalam penelitian ini sebagai berikut.

1. Observasi, yaitu mengadakan penelitian dengan melakukan pengamatan dengan cermat secara langsung untuk mengetahui kondisi pada tempat penelitian mengenai masalah yang diteliti serta mengadakan pencatatan terhadap data yang diperlukan seperti keadaan Subak Semujan, kepengurusan Subak Semujan, dan awig-awig di Subak Semujan.

2. Wawancara, yaitu mengadakan tanya jawab secara langsung dengan informan menggunakan kuisioner penelitian secara terstruktur. Wawancara mendalam digunakan untuk mengambil berbagai informasi secara lebih mendalam dengan informan kunci (pengurus subak).

3. Dokumentasi adalah kegiatan yang bertujuan untuk mengumpulkan data dengan cara mengambil gambar berupa foto-foto, video, dan lain sebagainya di lokasi penelitian guna mendukung teknik pengumpulan data lain.

\subsection{Penentuan Informan Kunci}

Penentuan informan kunci dalam penelitian ini menggunakan teknik purposive sampling. Adapun informan kunci yang dijadikan sumber data dalam penelitian ini adalah pengurus Subak Semujan, I Nyoman Sudariasta pekaseh (ketua), I Wayan Kendit penyarikan (sekretaris), dan I Nyoman Sadri patengenan (bendahara). Dari informan kunci tersebut diperoleh tujuh orang informan dengan teknik snowball sampling sehingga diperoleh 10 informan secara keseluruhan. Pengambilan informan sebanyak 10 orang tersebut menggunakan teknik snowball sampling diamana merupakan teknik multitahap dimana didasarkan pada analogi bola salju yang dimulai dalam ukuran kecil, tetapi seiring proses jumlahnya semakin membesar (Imbrahim, 2015).

\subsection{Analisis Data}

Metode analisis data yang digunakan dalam penelitian ini adalah analisis deskriptif kualitatif. Penelitian diawali dengan menentukan kekuatan, kelemahan, peluang dan ancaman yang dimiliki oleh Subak Semujan. Dianalisis menggunakan analisis lingkungan internal (IFAS), lingkungan eksternal (EFAS) untuk mengetahui bobot, rating dan skor masing-masing faktor. Masing-masing skor akan dilanjutkan dengan matriks I-E untuk memperoleh strategi di tingkat korporat yang lebih detail dan matriks SWOT digunakan untuk menyusun faktor-faktor strategi dengan menggambarkan secara jelas peluang dan ancaman dengan kekuatan dan kelemahan yang dimiliki. 


\section{Hasil dan Pembahasan}

\subsection{Identifikasi Analisis Lingkungan Internal dan Eksternal}

\subsubsection{Identifikasi faktor lingkungan internal}

Pearce dan Robinson, (dalam Kotler, 2005), analisis lingkungan internal adalah pengertian mengenai pencocokan kekuatan dan kelemahan internal dengan peluang dan ancaman eksternal yang berada di dalam Subak Semujan. Berdasarkan hasil identifikasi lingkungan internal maka dapat diketahui faktor-faktor kekuatan dan kelemahan. Adapun faktor lingkungan internal Subak Semujan adalah sebagai berikut.

1. Faktor kekuatan, yaitu: (a) kegiatan upacara keagamaan masih tetap berlangsung, (b) kegiatan gotong royong masih rutin dilaksanakan, (c) kegiatan rapat subak masih tetap dilaksanakan (peparuman), (d) keadaan infrastruktur yang memadai, (e) penerapan aturan yang mengikat subak (awig-awig/pararem) masih tetap berjalan, dan (f) aktivitas pertanian masih berlangsung sebagai daya tarik pariwisata.

2. Faktor kelemahan, yaitu: (a) kemampuan pengurus mengenai administrasi lemah, (b) pendidikan pengurus subak rendah, (c) kemampuan anggota subak dalam mengadopsi inovasi atau teknologi baru rendah, dan (d) kurangnya minat anak petani dalam bertani. Berdasarkan identifikasi kekuatan dan kelemahan akan dilanjutkan dengan pemberian suatu bobot dan rating pada setiap indikator dapat diperoleh skor masing-masing faktor internal dengan matriks IFAS. Berikut adalah hasil perhitungan matriks IFAS yang dapat dilihat pada tabel 1 di bawah ini.

Tabel 1.

Analisis Matriks IFAS Strategi Bertahan Subak Semujan di Daerah Pariwisata, Kecamatan Ubud, Kabupaten Gianyar Tahun 2017

\begin{tabular}{|c|c|c|c|c|}
\hline \multicolumn{5}{|c|}{ Faktor Internal } \\
\hline No & Kekuatan & Bobot & Rating & Skor \\
\hline 1 & Kegiatan upacara keagamaan masih tetap berlangsung & $\mathbf{0 , 1 0}$ & 4 & $\mathbf{0 , 4 0}$ \\
\hline 2 & Kegiatan gotong royong masih rutin dilaksanakan & 0,08 & 3 & 0,24 \\
\hline 3 & $\begin{array}{l}\text { Kegiatan rapat subak (peparuman) masih tetap } \\
\text { dilaksanakan }\end{array}$ & 0,09 & 3 & 0,27 \\
\hline 4 & Keadaan infrastruktur yang memadai & 0,08 & 3 & 0,24 \\
\hline 5 & $\begin{array}{l}\text { Penerapan aturan yang mengikat subak (awig- } \\
\text { awig/pararem) masih tetap berjalan }\end{array}$ & 0,09 & 4 & $\mathbf{0 , 3 6}$ \\
\hline 6 & $\begin{array}{l}\text { Aktivitas pertanian masih berlangsung sebagai daya } \\
\text { tarik pariwisata }\end{array}$ & 0,06 & 3 & 0,18 \\
\hline \multicolumn{5}{|c|}{ Kelemahan } \\
\hline 1 & Kemampuan pengurus mengenai administrasi lemah & 0,09 & 3 & 0,27 \\
\hline 2 & Pendidikan pengurus subak rendah & 0,11 & 2 & 0,22 \\
\hline 3 & $\begin{array}{l}\text { Kemampua anggota subak dalam mengadopsi inovasi } \\
\text { atau teknologi baru rendah }\end{array}$ & $\mathbf{0 , 1 4}$ & 2 & 0,28 \\
\hline 4 & Kurangnya minat anak petani dalam bertani & $\mathbf{0 , 1 6}$ & 2 & $\mathbf{0 , 3 2}$ \\
\hline & Total & 1,00 & 29 & 2,78 \\
\hline
\end{tabular}

Keterangan: cetak tebal adalah nilai tertinggi

Berdasarkan tabel 1 faktor internal yang dimiliki Subak Semujan faktor kekuatan nilai skor tertinggi adalah kegiatan upacara keagamaan masih tetap berlangsung dengan 
perolehan nilai skor sebesar 0,40. Faktor kekuatan selanjutnya dengan nilai skor 0,36 adalah penerapan aturan yang mengikat subak (awig-awig/pararem) masih tetap berjalan. Faktor tersebut memiliki nilai bobot 0,10 dan 0,09 dengan nilai rating 4 yang berarti kedua faktor tersebut kuat. Kegiatan upacara keagamaan seperti ngodalin di Pura Bedugul, magpag toya, ngendag mangkal, ngurit, dan biyukukung adalah menjadi salah satu kekuatan yang menyebabkan Subak Semujan masih dapat bertahan. Kegiatan upacara keagamaan mencerminkan nilai Tri Hita Kara dalam aspek parhyangan yang dimana memiliki arti hubungan harmonis antara manusia dengan Tuhan atau sang pencipta sebagai rasa syukur atas karuniaNya.

Faktor kekuatan lain, yang menyebabkan Subak Semujan dapat bertahan adalah masih tetap berlangsungnya penerapan aturan yang mengikat subak (awigawig/pararem). Awig-awig dan pararem menjadi kekuatan Subak Semujan dikarenakan mampu mengikat dan bersifat memaksa bagi seluruh anggota subak dalam menjalankan kegiatan persubakan sesuai kesepakatan bersama. Adanya sanksi yang diberikan kepada anggota subak bila mana melanggar awig-awig/pararem menjadikan penerapan aturan tersebut yang mengikat di subak sangat dipatuhi bersama.

Faktor kelemahan yang utama dalam bertahannya Subak Semujan di daerah pariwisata adalah kurangnya minat anak petani dalam bertani dengan nilai skor 0,32 dan nilai bobot 0,16 dan disusul dengan kemampuan anggota subak dalam mengadopsi inovasi maupun teknologi baru rendah dengan perolehan nilai skor sebesar 0,28 dan dengan perolehan nilai bobot 0,14 . Kurangnya minat anak petani akan berakibat terancamnya keberadaan Subak Semujan karena tidak adanya penerus sebagai petani di subak, jika hal ini tidak diatasi maka kemungkinan besar subak semakin ditinggalkan dan keberadaannya menjadi hilang. Rendahnya kemampuan anggota subak dalam mengadopsi inovasi seperti penggunaan traktor, bibit unggul dan penggunaan pestisida nabati maupun teknologi baru rendah karena tingkat pendidikan anggota Subak Semujan yang rendah sehingga berpengaruh terhadap keberlanjutan subak. Total skor faktor internal berdasarkan perhitungan matriks IFAS adalah sebesar 2,78 yang berarti termasuk kedalam kategori kuat, karena total yang berada di bawah 2,5 menandakan faktor strategi internal yang lemah, menunjukan bahwa Subak Semujan mampu memanfaatkan kekuatan untuk menghindari kelemahan (Rangkuti, 2016).

\subsubsection{Identifikasi faktor lingkungan eksternal}

Menurut Dirgantoro (2007), lingkungan eksternal bisa dikatakan sebagai komponen-komponen atau variabel lingkungan yang berada atau berasal dari luar Subak Semujan.

1. Faktor peluang, yaitu: (a) adanya bantuan sosial dan sarana produksi padi, (b) adanya fasilitas pasar tradisional untuk pemasaran hasil panen dari subak, (c) pariwisata sebagai pasar produk pertanian subak, dan (d) adanya penyuluhan pertanian dari PPL dan media massa.

2. Faktor ancaman, yaitu: (a) peluang kerja sektor pariwisata, (b) usaha pariwisata yang memerlukan lahan pertanian, (c) masuknya pekerja dari luar, (d) pencemaran saluran air irigasi, dan (e) harga produk pertanian rendah. Berdasarkan identifikasi peluang dan ancaman dilanjutkan dengan pemberian bobot dan rating maka dapat diperoleh skor masing-masing faktor eksternal yang lazim disebut dengan matriks EFAS. Dapat dilihat pada tabel 2. 
Tabel 2.

Analisis Matriks IFAS Strategi Bertahan Subak Semujan di Daerah Pariwisata, Kecamatan Ubud, Kabupaten Gianyar Tahun 2017

\begin{tabular}{clccc}
\hline \multicolumn{1}{c}{ Faktor Eksternal } & & & \\
\hline No & \multicolumn{1}{c}{ Peluang } & Bobot & Rating & Skor \\
\hline 1 & Adanya bantuan sosial dan sarana produksi padi & $\mathbf{0 , 1 7}$ & 3 & $\mathbf{0 , 5 1}$ \\
2 & $\begin{array}{l}\text { Adanya fasilitas pasar tradisional untuk pemasaran hasil } \\
\text { panen pertanian dari subak }\end{array}$ & 0,13 & 2 & 0,26 \\
3 & $\begin{array}{l}\text { Pariwisata sebagai pasar produk pertanian subak } \\
\text { Adanya penyuluhan pertanian dari PPL dan media massa }\end{array}$ & 0,05 & 2 & 0,10 \\
& $\quad$ Ancaman & 2 & $\mathbf{0 , 3 0}$ \\
\hline & $\quad$ & $\mathbf{0 , 1 3}$ & 2 & $\mathbf{0 , 2 6}$ \\
\hline 1 & Peluang kerja sektor pariwsata & $\mathbf{0 , 1 5}$ & 2 & $\mathbf{0 , 3 0}$ \\
3 & Usaha pariwisata yang memerlukan lahan pertanian & 0,10 & 2 & 0,20 \\
4 & Masuknya pekerja dari luar & 0,04 & 3 & 0,12 \\
5 & Pencemaran saluran air irigasi & 0,09 & 2 & 0,18 \\
\hline & $\quad$ Targa produk pertanian rendah & 1,00 & 20 & 2,23 \\
\hline
\end{tabular}

Keterangan: cetak tebal adalah nilai tertinggi

Berdasarkan tabel 2 faktor eksternal peluang terpenting yang utama, yaitu adanya bantuan sosial dan sarana produksi padi dan adanya penyuluhan pertanian dari PPL dan media massa memperoleh nilai skor 0,51 dan 0,30 dengan nilai bobot sebesar 0,17 dan 0,15 dengan masing-masing dapat nilai 3 dan 2 yang berarti kuat. Bantuan sosial dan sarana produksi padi dan penyuluhan pertanian dari pemerintah merupakan salah satu bentuk upaya pelestarian subak oleh pemerintah. Bantuan sosial dan sarana produksi padi seperti bantuan bibit, pupuk, dan jalan usaha tani di mana dengan adanya bantuan ini diharapkan petani di Subak Semujan tetap mau berusaha tani sehingga subak dapat lestari atau bertahan khususnya subak di daerah pariwisata.

Ancaman yang paling mengancam adalah usaha pariwisata yang memerlukan lahan pertanian dengan perolehan skor 0,30 dan nilai bobot sebanyak 0,15. Adanya ancaman usaha pariwisata yang memerlukan lahan pertanian menjadi ancaman yang paling mengancam bagi kelestarian Subak Semujan. Pembangunan fasilitas pariwisata seperti hotel, villa, bungalow, dan restaurant oleh pariwisata yang menggunakan lahan pertanian semakain mengancam keberadan Subak Semujan itu sendiri. Ancaman yang tidak kalah penting adalah peluang kerja sektor pariwisata dengan perolehan skor 0,26 dengan nilai bobot sebanyak 0,13. Adanya ancaman tersebut diperlukan upaya atau usaha untuk menghadapi ancaman dengan menguatkan awig-awig/pararem yang ada sebelumnya dengan membuat aturan yang mengatur secara khusus mengenai alih fungsi lahan pertanian di subak. Total skor faktor eksternal berdasarkan perhitungan matriks EFAS adalah sebesar 2,23 yang berarti termasuk kedalam kategori rendah karena total yang berada di bawah 2,5 termasuk rendah, menunjukan bahwa Subak Semujan sampai sekarang ini dapat bertahan namun belum mampu memanfaatkan peluang untuk mengatasi ancaman yang ada (Rangkuti, 2016).

\subsection{Analisis Matriks Internal-Eksternal (I-E)}

Strategi ini akan menghasilkan matriks I-E yang dapat mengetahui bagaimana arah dan posisi Subak Semujan saat ini sehingga dapat memberikan pilihan alternatif strategi. Berdasarkan skor dari matriks I-E yaitu skor IFAS sebesar 2,78 yang menggambarkan bahwa Subak Semujan berada dalam kondisi internal sedang, 
sedangkan skor EFAS sebesar 2,23 yang menggambarkan bahwa Subak Semujan sampai sekarang ini dapat bertahan. Adapun hasil dari perhitungan matriks I-E strategi bertahan Subak Semujan di daerah pariwisata dapat diihat pada gambar 1.

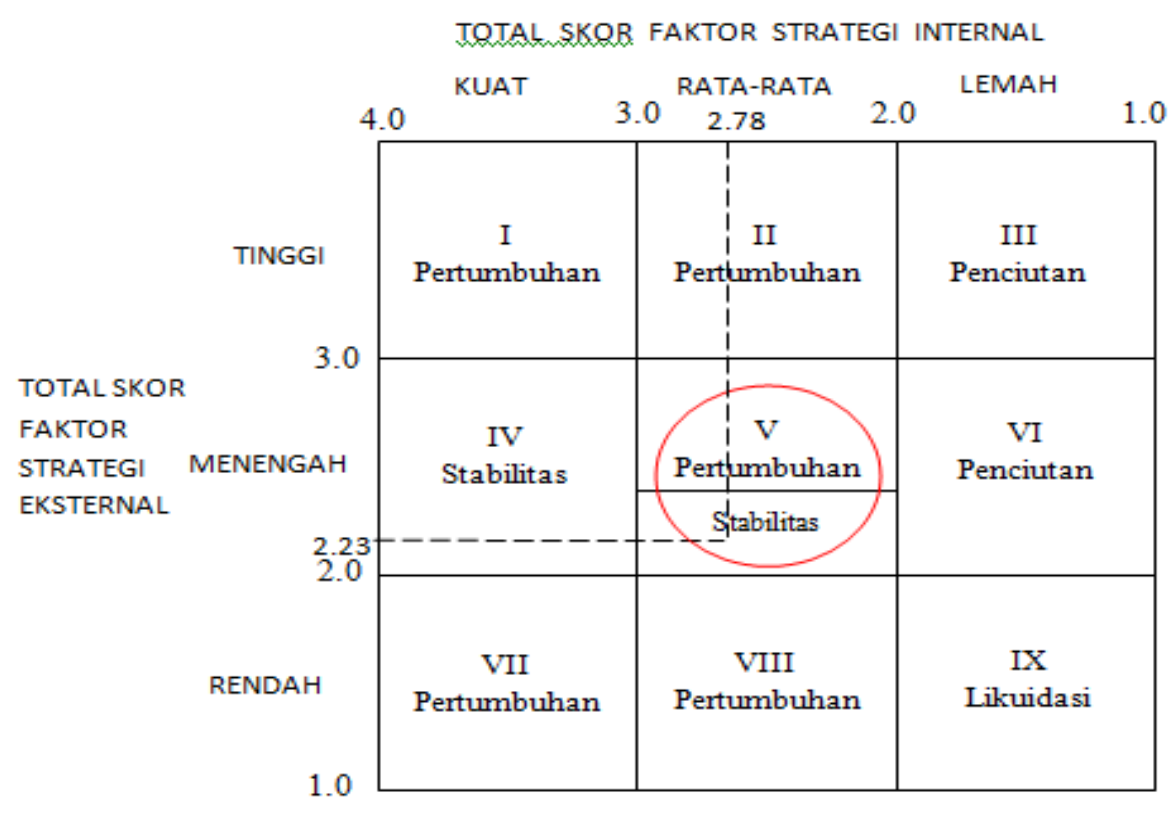

Gambar 1.

Matriks Internal-Eksternal (I-E) Strategi Bertahan Subak Semujan di Daerah Pariwisata, Kecamatan Ubud, Kabupaten Gianyar Tahun 2017

Berdasarkan gambar 1 pemetaan ditunjukan dengan garis putus-putus pada matriks I-E dimana sumbu $X$ yang merupakan input dari matriks IFAS dengan perolehan skor sebesar 2,78 dan pada sumbu Y yang merupakan matriks EFAS dengan perolehan skor sebesar 2,23. Pertemuan sumbu X dan sumbu Y berada pada sel V yaitu stabilitas di mana pada posisi ini menunjukan bahwa Subak Semujan saat ini pada posisi bertahan di mana diliat dari adanya ancaman dari pariwisata yang memerlukan lahan pertanian sebegai usaha pariwisata seperti hotel, bungalow, villa, dan restaurant. Subak Semujan mampu bertahan sampai sekarang ini dapat dilihat dari berjalannya kegiatan upacara keagamaan di subak, penerapan awig-awig dan pelaksanaan gotong royang di subak.

\subsection{Penentuan Alternatif Strategi Melalui Matriks SWOT}

Berbagai alternatif strategi dapat dirumuskan berdasarkan analisis matriks SWOT. Pada matriks ini difokuskan untuk menghasilkan alternatif strategi yang layak dengan memadukan faktor internal dan faktor eksternal, matriks ini dapat menggambarkan secara jelas bagaimana peluang dan ancaman eksternal yang dihadapi dapat disesuaikan dengan kekuatan dan kelemahan yang dimiliki subak. Empat sel kemungkinan yang dihasilkan yaitu strategi S-O,S-T,W-O, dan W-T. Matriks Analisis SWOT strategi bertahan Subak Semujan di daerah pariwisata dapat dilihat pada tabel 3. 
Tabel 3.

Penyusunan Alternatif Strategi Menggunakan Matriks SWOT Subak Semujan, Kecamatan Ubud, Kabupaten Gianyar Tahun 2017

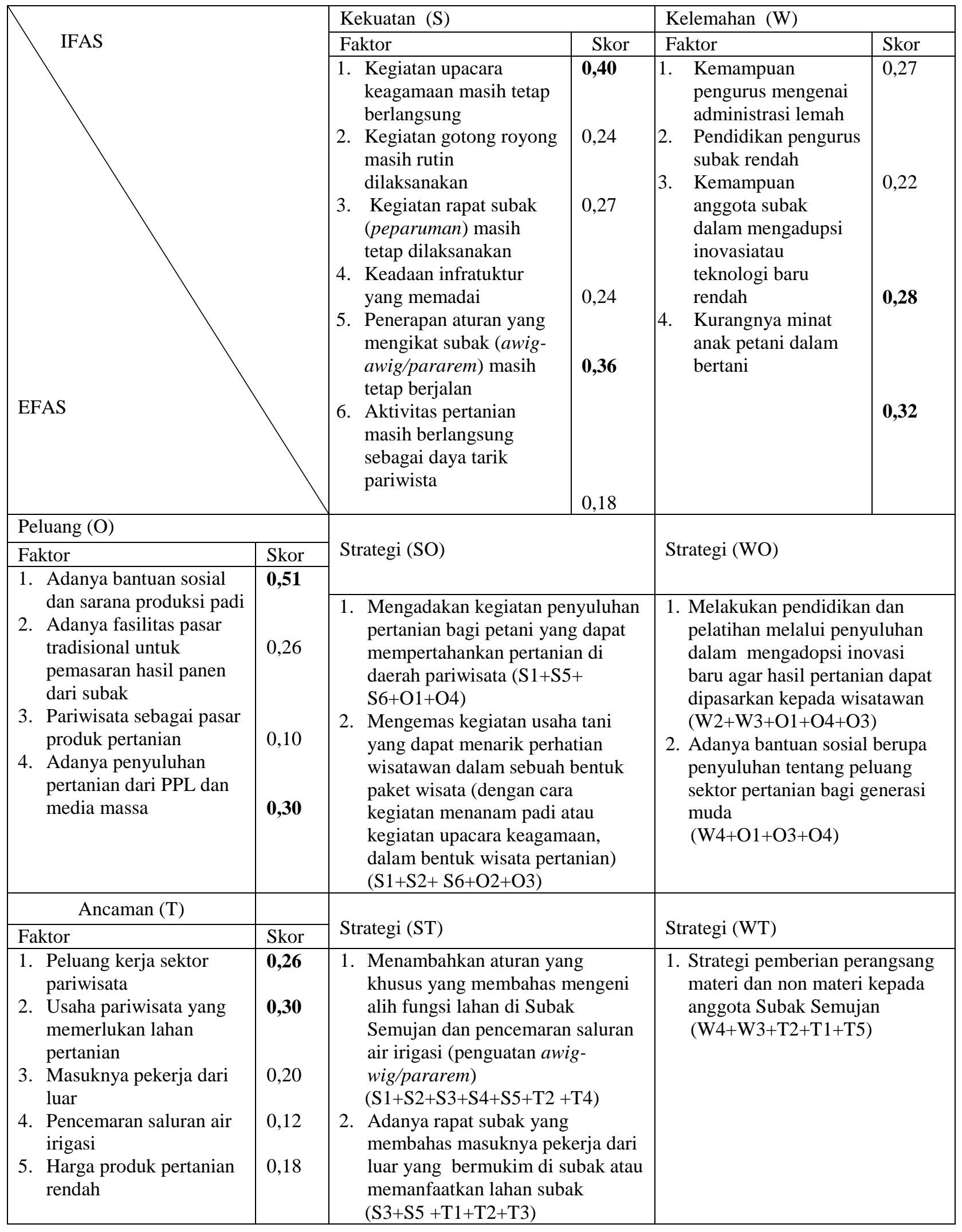


Berdasarkan tabel 3 diperoleh beberapa alternatif strategi seperti, strategi S-O mengadakan kegiatan penyuluhan pertanian bagi petani yang dapat mempertahankan pertanian di daerah pariwisata serta mengemas kegiatan usaha tani yang dapat menarik perhatian wisataman dalam sebuah bentuk paket wisata. Strategi S-T adalah menambahkan aturan yang khususnya membahas mengeni alih fungsi lahan di Subak Semujan dan pencemaran saluran air irigasi (penguatan awig-wig/pararem) dan adanya rapat subak yang membahas masuknya pekerja dari luar yang bermukim di subak atau memanfaatkan lahan subak. Strategi W-O adalah melakukan pendidikan dan pelatihan melalui penyuluhan dalam mengadopsi inovasi baru agar hasil pertanian dapat dipasarkan kepada wisatawan serta adanya bantuan sosial berupa penyuluhan tentang peluang sektor pertanian bagi generasi muda. Strategi W-T adalah strategi pemberian perangsang meteri dan non materi kepada anggota Subak Semujan. Berdasarkan hasil matriks SWOT maka prioritas utama yang harus dilakukan adalah menambahkan aturan yang khusus yang membahas mengenai alih fungsi lahan di subak.

\section{Kesimpulan dan Saran}

\subsection{Kesimpulan}

Berdasarkan hasil penelitian yang telah dibahas sebelumnya, maka dapat ditarik beberapa simpulan sebagai berikut.

1. Beberapa alternatif strategi Subak Semujan dalam bertahan di daerah pariwisata : (a) Strategi S-O mengadakan kegiatan penyuluhan pertanian bagi petani yang dapat mempertahankan pertanian di daerah pariwisata serta mengemas kegiatan usaha tani yang dapat menarik perhatian wisatawan dalam sebuah bentuk paket wisata pertanian, (b) Strategi S-T menambahkan aturan yang khususnya membahas mengeni alih fungsi lahan di Subak Semujan dan pencemaran saluran air irigasi (penguatan awig-wig/pararem) dan adanya rapat subak yang membahas masuknya pekerja dari luar yang bermukim di subak atau memanfaatkan lahan subak, (c) Strategi W-O melakukan pendidikan dan pelatihan melalui penyuluhan dalam mengadopsi inovasi baru agar hasil pertanian dapat dipasarkan kepada wisatawan serta adanya bantuan sosial berupa penyuluhan tentang peluang sektor pertanian bagi generasi muda, dan (d) Strategi W-T pemberian perangsang meteri dan non materi kepada anggota Subak Semujan.

2. Berdasarkan hasil matriks SWOT maka prioritas utama yang harus dilakukan di Subak Semujan adalah penguwatan awig-awig/pararem dengan membuat aturan yang khusus membahas mengenai alih fungsi lahan di subak guna mengatasi ancaman usaha pariwista yang memerlukan lahan pertanian.

\subsection{Saran}

Berdasarkan temuan dalam penelitian ini, maka saran yang dapat diberikan sebagai berikut.

1. Bagi Subak Semujan, (a) memperbaiki kemampuan anggota subak yang rendah dalam mengadopsi inovasi (teknologi baru) dengan cara mengikuti pelatihanpelatihan, (b) penguatan awig-awig/pararem di subak, yang membuat peraturan yang khusus membahas mengenai alih fungsi lahan di Subak Semujan, (c) menjaga serta mempertahankan kegiatan upacara keagamaan, kegiatan gotong royang yang merupakan nilai-nilai Tri Hita Karana yang dimiliki subak, dan (d) mengimplementasikan alternatif strategi yang direkomendasikan berdasarkan hasil penelitian ini. 
2. Bagi pemerintah, diharapkan agar dapat memberikan berbagai kebijakan yang khusus mendukung pelestarain subak seperti penerapan bebas pajak bagi lahan subak, penyuluh pertanian dan pendampingan secara lebih intensip dalam penerapan inovasi (teknologi baru) di subak. Pemerintah diharapkan memberikan perangsang yang diperlukan oleh subak sehingga dapat mensejahterakan petani di subak. Pemerintah diharapkan juga memberikan batasan dimana saja boleh membangun dan pembentukan subak lestari, dimana subak lestari berupa konsep agar mempertahankan subak seperti keadaan semula, tidak berubah dan bertahan.

\section{Ucapan Terimakasih}

Terimakasih kepada semua pihak yang telah memberikan bantuan berupa data, buah pikiran, kebendaan dan lain-lain sehingga e-jurnal ini dapat diselesaikan dengan baik. Semoga hal didalamnya bermanfaat adanya.

\section{Daftar Pustaka}

Budiastuti, Putu. 2015. Upaya Pelestarian Subak di Perkotaan. Skripsi. Fakultas Pertanian Universitas Udayana.

BPP. 2016. Luas Baku Lahan Sawah Tahun 2016 Kecamatan Ubud. Balai Pelatihan Pertanian, Kecamatan Ubud. Ubud. BPP Kecamatan Ubud.

Dirgantoro, C. (2007). Manajemen Stratejik. Grasindo. Jakarta.

Ibrahim, M. A. 2015. Metodelogi Penelitian Kualitatif. Alfabeta. Bandung.

Maulidi, Achmad. 2016. Pengertian Data Primer dan Data Sekunder. https://www.kanalinfo.web.id/2016/10/pengertian-data-primer-dan-sekunder.html (diakses pada tanggal 18 Januari 2017).

Kotler Philip. 2005. Manajemen Pemasaran, Jilid 1, PT. Indeks Kelompok. Gramedi. Jakarta.

Pitana, I Gde. 1993. Subak, Sistem Irigasi Tradisional di Bali (Sebuah Deskripsi Umum) dalam Pitana, I Gde (Editor). 1993. Subak: Sistem Irigasi Tradisional di Bali (Sebuah Canangsari). Penerbit Upada Sastra. Denpasar.

Rangkuti, Freddy. 2016 Analisis SWOT Teknik Membedah Kasus Bisnis. Penerbit PT Gramedia Pustaka Utama. Jakarta.

Sugiyono. 2012. Metode Penelitian Pendidikan: Pendekatan Kuantitatif, Kualitatif dan $R \& D$. Bandung. Alfabeta.

Windia, Wayan. 2016. Transformasi Sistem Irigasi yang Berlandaskan Tri Hita Karana. Pustaka Bali Post. Denpasar. 